\title{
Analisis Kontras Spekel menggunakan LSI (Laser Speckel Imaging) untuk Mendeteksi Formalin pada Tomat (Lycopersicum Esculentum Mill)
}

\author{
Neneng Fitrya* \\ Program Pascasarjana FMIPA Universitas Andalas, Kampus Limau Manis, Padang 25163 \\ Sandra \\ Departemen Teknik Pertanian, Fakultas Teknik Pertanian, \\ Universitas Andalas, Kampus Limau Manis, Padang 25163 \\ Harmadi \\ Departemen Fisika, FMIPA Universitas Andalas, Kampus Limau Manis, Padang $25163^{\dagger}$
}

Intisari

Telah dilakukan pendeteksian formalin pada tomat dengan menggunakan metode LSI (Laser Spekcle Imaging). Sistem LSI terdiri dari tiga komponen utama yaitu laser sebagai sumber cahaya, sampel dan sebuah detektor cahaya. Pecitraan pola spekel dengan metode LSI mendeteksi perubahan intensitas laser spekel yang dihamburkan oleh sampel dan dianalisis sebagai kontras spekel. Pola spekel dianalisis menggunakan software imageJ dan diperoleh karakterisasi histogram distribusi intensitas gray level. Perubahan pola spekel tomat dapat digunakan untuk membedakan tomat yang berformalin dengan yang tidak berformalin. Dilakukan penyinaran terhadap tomat sebelum dan sesudah direndam larutan formalin dengan variasi konsentrasi $0,001 \%, 0,005 \%$, $0,01 \%, 0,05 \%$, dan variasi waktu perendaman yaitu selama 15 menit dan perendaman selama 30 menit. Secara umum korelasi kontras spekel dengan formalin pada tomat, menunjukkan bahwa formalin terdeteksi dengan perubahan kontras spekel pada tomat. Semakin tinggi konsentrasi formalin dan waktu perendaman nilai kontras spekel semakin kecil.

\begin{abstract}
Has been performed formaldehyde detection on tomatoes using LSI (Laser Spekcle Imaging) method. LSI system consists of three main components, wich is a laser as a light source, a sample and a light detector. The imaging of speckle pattern with LSI method detects changes in the intensity of the laser speckle that is scattered by the sample, and analyzed as speckle contrast. Speckle pattern was analyzed using ImageJ software and obtained characterization gray level intensity distribution histogram. Change in contrast value of the speckle pattern of tomatoes can be used to distinguish the tomatoes with and without formaldehyde. Irradiation is carried out on tomato before and after the tomato soaked with various concentration of formaldehyde solution $2 \%, 3 \%, 4 \%, 5 \%$ and the variation immersion time for 15 minutes and 30 minutes. In general, the speckle contrast correlation with formaldehyde in tomatoes, showed that formaldehyde was detected by speckle contrast changes in tomatoes. The higher concentration of formaldehyde and immersion time, speckle contrast value will get smaller.
\end{abstract}

KATA KUNCI: speckle pattern, contrast, LSI (Laser Speckle Imaging), formaldehyde

\section{PENDAHULUAN}

Spekel merupakan pola intensitas acak yang dihasilkan oleh interferensi cahaya terhambur dari permukaan yang disinari berkas cahaya koheren. Teknik spekel merupakan salah satu teknik optik dalam pengujian yang bersifat tidak merusak bahan. Salah satu teknik non-imaging dan non-destructive yang

\footnotetext{
*E-MAIL: neng_fitrya@yahoo.co.id

${ }^{\dagger}$ E-MAIL: harmadi@fmipa. unand.ac.id
}

digunakan untuk mendeteksi sinyal optik dari jaringan biologi adalah metode LSI (Laser Speckle Imaging) [1]. Pada metode ini, material disinari berkas koheren dari laser, terjadi hamburan dan membentuk pola spekel pada bidang pengamatan [2].

Sistem pencitraan spekel mendeteksi perubahan intensitas spekel laser yang didifraksikan pada sampel dengan analisis kontras spekel [3]. Analisa kontras yang digunakan adalah analisa intensitas gray level (tingkat keabu-abuan) dari hasil citra suatu sistem pencitraan spekel laser dengan menggunakan histogram yang digunakan untuk klasifikasi dan pencocokan pola. Sistem LSI ini memiliki kesederhanaan dalam 
pengesetan karena hanya terdiri dari tiga komponen utama yaitu laser sebagai sumber cahaya, sampel dan sebuah detektor cahaya. Keunggulan LSI adalah minim efek samping (non destructive, non invasive, non ionisasi) [4], memiliki pencitraan penuh, akuisisi data langsung, akurat, kuantitatif dan biaya rendah [5].

Masalah utama tomat setelah dipanen adalah sifatnya yang mudah rusak oleh pengaruh mekanis serta kandungan air yang tinggi, sehingga memungkinkan adanya aktivitas enzim dan mikroorganisme pembusuk. Kulit tomat sangat mudah mengalami kerusakan karena goresan atau gesekan sehingga diperlukan penanganan pasca panen yang benar [6], agar sesampainya di tangan konsumen tomat tetap dalam keadaan segar dengan warna yang menarik. Beberapa pihak melakukan penanganan pasca panen yang tidak wajar dengan melakukan pengawetan menggunakan bahan berbahaya seperti formalin. Formalin sangat berbahaya bagi tubuh. Akibat yang ditimbulkan dapat berupa luka bakar pada kulit, iritasi pada saluran pernafasan, reaksi alergi dan bahaya kanker pada manusia.

Pengembangan metode LSI ini dapat diaplikasikan pada buah-buahan untuk melihat apakah buah tersebut berformalin atau tidak dengan prinsip hamburan cahaya laser yang ditembakkan pada buah sehingga didapatkan pola spekel dari buah tersebut. Analisis perubahan kontras pola spekel yang dapat digunakan untuk membedakan tomat yang berformalin dengan yang tidak berformalin.

\section{MATERIAL DAN METODOLOGI}

Pengujian pada buah-buahan menggunakan sistem laser spekel dengan prinsip hamburan cahaya. Ketika berkas koheren dari laser dikenakan pada permukaan bahan, maka terbentuklah pola interferensi yang khas dalam bentuk suatu granular (butiran) bernama spekel [8]. Pola gelap terang dari spekel terjadi karena frekuensi yang berbeda. Deskripsi tentang statistik distribusi intensitas yang dihasilkan oleh spekel, diasumsikan bahwa medan yang koheren dengan panjang gelombang $\lambda$ menerangi permukaan suatu bahan yang berarti panjang gelombang yang dipilih memiliki ukuran yang lebih kecil dari bahan yang digunakan. Kekasaran suatu bahan akan menyebabkan distribusi intensitas dan fase yang acak. Hal ini berhubungan dengan nilai mean. Bidang cahaya dalam suatu ruang pada titik tertentu $\mathrm{P}(\mathrm{x}, \mathrm{y}, \mathrm{z})$ dalam pola spekel haruslah merupakan jumlah dari total hamburan $\mathrm{N}$, yang mewakili distribusi dari semua titik pada permukaan yang terhambur. Jika diberi pencahayaan dari cahaya monokromatik maka cahaya terhambur terhadap bidang P yang dihasilkan oleh setiap elemen permukaan dijabarkan [1], diberikan oleh persamaan:

$$
u_{j}(P)=\left|u_{j}\right| e^{i \phi_{j}}=\left|u_{j}\right| e^{i k r_{j}}
$$

adalah jarak (variasi acak) dari elemen hamburan permukaan ke j pada titik P. Amplitudo kompleks medan hamburan di titik
P dituliskan pada Pers. 2:

$$
\begin{aligned}
U_{j}(P) & =\frac{1}{\sqrt{N}} \sum_{j=1}^{N} u_{j}(P) \sum=\frac{1}{\sqrt{N}} \sum_{j=1}^{N}\left|u_{j}\right| e^{i \phi_{j}} \\
& =\frac{1}{\sqrt{N}} \sum_{j=1}^{N}\left|u_{j}\right| e^{i k r_{j}}
\end{aligned}
$$

Penjumlahan dalam Pers.(2) merupakan cara acak dalam bidang kompleks, dengan fasa acak $\phi_{j}=\mathrm{kr}_{j}$.

Dengan mengasumsikan amplitudo $\mathrm{u}_{j}$ dan fase $\phi_{j}$ pada setiap komponen medan secara statistik independent (bebas/ tidak bergantung) satu sama lain, dan tidak bergantung dari amplitudo dan fase komponen medan lainnya. Fase $\phi_{j}$ didistribusikan secara menyeluruh pada interval $(-\pi, \pi)$, yang berarti bahwa permukaan kasar dibandingkan dengan panjang gelombang, dan jumlah hamburan total $\mathrm{N}$ sangat besar, sehingga menjamin validitas dari teotema limit sentral. Goodman telah menunjukkan bahwa bagian riel dan imajiner dari medan resultan adalah asimtotik Gaussian [9]. Fungsi densitas probabilitas bersama diberikan oleh Pers.(3).

$$
P_{r, i}\left(U^{(r)}, U^{(i)}\right)=\frac{1}{2 \pi \sigma^{2}} \exp \left[\frac{\left(U^{(r)}\right)^{2}+\left(U^{(i)}\right)^{2}}{2 \sigma^{2}}\right]
$$

Dengan nilai Circular Gaussian, adalah:

$$
\sigma^{2}=\lim _{N \rightarrow \propto} \sum_{j=1}^{N} \frac{\left\langle\left|u_{j}\right|\right\rangle^{2}}{2}
$$

Dari Pers. 3, dan dengan menghitung intensitas I dan fase $\phi$ medan resultan pada bagian riel dan imajiner medan mengacu pada Pers.(5).

$$
\begin{aligned}
U^{(r)} & =\sqrt{I} \cos \phi \\
U^{(i)} & =\sqrt{I} \sin \phi
\end{aligned}
$$

Selanjutnya probabilitas intensitas $\mathrm{p}(\mathrm{I})$ dan probabilitas fase $\mathrm{p}(\phi)$, diberikan oleh Pers.(6) dan 7

$$
\begin{array}{r}
p(I)=\frac{1}{\sqrt{I}} e^{-\frac{I}{\langle I\rangle}} \text { untuk } I \geq 0 \\
p(\phi)=\frac{1}{2 \pi} \text { untuk }-\pi \leq \phi \leq \pi
\end{array}
$$

Secara berturut-turut di dalam Pers.(6), $\langle I\rangle$ adalah nilai rata-rata intensitas pada diagram spekel. Menurut dua persamaan terakhir, distribusi intensitas mengikuti hukum eksponensial negatif dimana fase terdistribusi secara merata dalam interval $(-\pi, \pi)$. Distribusi kejadian intensitas didefinisikan pada Pers.(8).

$$
\langle I\rangle=n !\left(2 \sigma^{2}\right)^{n}=n !\langle I\rangle^{n}
$$

khusus pada orde kedua dinyatakan dalam Pers.(9).

$$
\begin{aligned}
\left\langle I^{2}\right\rangle & =2\langle I\rangle^{2} \\
\sigma_{1}^{2} & =\left\langle I^{2}\right\rangle-\langle I\rangle^{2}=\left\langle I^{2}\right\rangle
\end{aligned}
$$




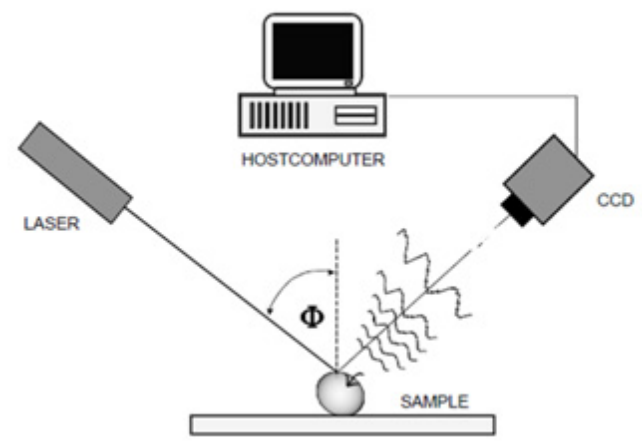

Gambar 1: Susunan rancangan spekel.

Persamaan ini menunjukkan bahwa standar deviasi dari pola spekel terpolarisasi sama dengan nilai rata-rata intensitas. Dengan menghitung pola modulasi spekel yang dinyatakan sebagai kontras, didefinisikan pada Pers.(10).

$$
C=\frac{\sigma_{I}}{\langle I\rangle}
$$

Kontras merupakan gabungan dari pola spekel yang menjadi kesatuan. Berdasarkan persamaan di atas, $\langle I\rangle$ adalah nilai rata-rata intensitas, $\sigma_{I}$ adalah standar deviasi dari intensitas, dan $\mathrm{C}$ adalah kontras.

Spekel adalah efek stokastik yang berhubungan dengan variabel acak yang didefinisikan pada ruang probabilitas, sehingga hanya dapat digambarkan secara statistik. Terdapat beberapa pendekatan statistik diantaranya adalah evaluasi statistik orde pertama dan kedua. Orde pertama adalah gambaran statistik dari intensitas dan kontras spekel pada suatu pola dalam citra tunggal. Pendekatan ini menunjukkan standar deviasi $(\sigma)$ intensitas adalah nilai rata-rata intensitas $\langle I\rangle$ pola spekel. Nilai kontras dapat dinyatakan sebagai $C$ dengan satuan a.u (arbitrary unit), dan ketika rasio bernilai 1, maka pola disebut memiliki konstras maksimum.

Sistem pencitraan optis ini digunakan untuk mendeteksi formalin pada buah, dengan menggunakan sumber laser continous wave $(\mathrm{CW})$ dari laser He-Ne yang memiliki intensitas lebih rendah dari cahaya tampak. Sumber cahaya laser He$\mathrm{Ne}$ yang diaplikasikan pada material bersifat tidak merusak (nonperturbing) atau tidak memberikan efek nyata terhadap sampel. Detektor yang digunakan adalah CCD karena bersifat sensitif terhadap cahaya. Sistem komputer digunakan sebagai penampil pencitraan spekel dan menganalisis citra menggunakan sistem optical image processing (pengolahan citra optik), sehingga diperoleh nilai kontras spekel. Susunan rancangan spekel dapat dilihat pada Gambar 1 . Pola spekel didapat dengan menggunakan perangkat sistem LSI yang terdiri dari sumber laser He-Ne dengan $\lambda=632,8 \mathrm{~nm}$ berdaya keluaran 0,8 $\mathrm{mW}$, sensor kamera CCD $30 \mathrm{fps}$ seri A4tech model PK-836F dan PC (Personal Computer) dengan software Ulead VideoStudio-7 sebagai komponen display visual untuk merekam dan menampilkan pola spekel.

Langkah penelitian adalah penyinaran terhadap tomat untuk mendapatkan pola spekel. Penyinaran dilakukan sebelum dan sesudah direndam larutan formalin dengan variasi kon- sentrasi $0,001 \%, 0,005 \%, 0,01 \%, 0,05 \%$, selama 15 menit dan perendaman selama 30 menit. Selanjutnya pengamatan terhadap kedua poal spekel yang didapat.

Pola spekel diolah dengan menggunakan software pengolah citra ImageJ, digunakan untuk mengolah citra pola spekel bahan uji melalui karakterisasi histogram intensitas tingkat keabu-abuan dari citra, sehingga dapat ditentukan kontras spekel dari sampel tomat tersebut. Selain itu, dilakukan juga pengamatan dengan mikroskop optik stereo Carton SPZT50 untuk melihat struktur permukaan tomat sebelum dan setelah direndam formalin. Pengamatan dilakukan dengan perbesaran 50 kali.

\section{HASIL DAN PEMBAHASAN}

Dari penelitian yang telah dilakukan, diperoleh bentuk pola spekel dari pencitraan spekel tomat. Analisis perubahan kontras pola spekel tomat dapat digunakan untuk membedakan tomat yang berformalin dengan yang tidak berformalin. Pola spekel yang dihasilkan berupa pola gelap dan terang yang merupakan hamburan acak dari tomat yang disinari laser dan hamburan balik tersebut ditangkap detektor. Berdasarkan hasil pengamatan pola spekel yang dipaparkan pada Gambar 2 (dalam skala keabu-abuan), terlihat secara umum bintik gelap dan terang terjadi dengan frekuensi kemunculan berbeda, dimana bintik gelap jauh lebih banyak daripada bintik terang. Pada Gambar 2 terlihat bahwa setiap perubahan konsentrasi dan penambahan waktu perendaman memperlihatkan perubahan kerapatan pola spekel, semakin tinggi konsentrasi formalin dan waktu perendaman pola spekel semakin rapat. Hasil pengamatan pola spekel citra sampel yang telah diperoleh, diproses menggunakan software ImageJ untuk mendapatkan karakterisasi histogram distribusi intensitas tingkat keabuabuan pada kondisi sebelum dan setelah direndam formalin. Analisis secara statistik menggunakan karakteristik histogram menampilkan distribusi intensitas tingkat keabu-abuan citra yang bervariasi di setiap titik dalam citra, sehingga dapat ditentukan nilai rata-rata intensitas $\langle I\rangle$ dan simpangan baku intensitas $\sigma_{I}$ yang merupakan ukuran variasi simpangan intensitas dari keseluruhan citra tersebut. Berdasarkan perolehan nilai rata-rata intensitas dan simpangan baku intensitas keseluruhan citra, maka dapat ditentukan kuantitas citra dalam bentuk kontras spekel $\mathrm{C}$, yang merupakan rasio antara simpangan baku intensitas $\sigma_{I}$ dengan nilai rata-rata intensitas.

Secara keseluruhan diperoleh perubahan nilai kuantitas citra pola spekel dalam bentuk kontras spekel sampel tomat pada kondisi sebelum dan setelah direndam formalin pada konsentrasi tertentu dengan variasi waktu perendaman. Niai kontras spekel tomat sebelum direndam formalin berkisar 0,382872 a.u, 0,382588 a.u, 0,390542 a.u, 0,384238 a.u. Sedangkan setelah direndam formalin dengan variasi konsentrasi selama 15 menit nilai kontras tomat berkisar 0,361957 a.u, 0,357846 a.u, 0,352675 a.u, 0,351871 a.u, ketika direndam selama 30 menit nilai kontras berkisar 0,359238 a.u, 0,345879 a.u, 0,333131 a.u, dan 0.315479 a.u. Secara umum pada sampel tomat terjadi perubahan nilai kontras spekel sebelum dan setelah direndam dengan formalin, dimana nilai 


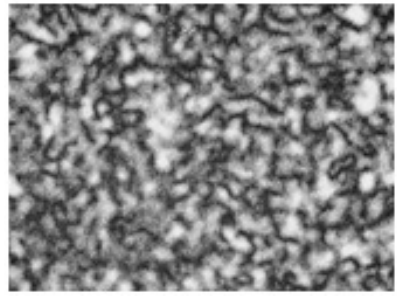

(a) Tanpa fomalin

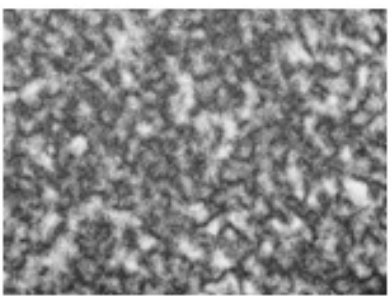

(b) $0,001 \%, 15$ menit

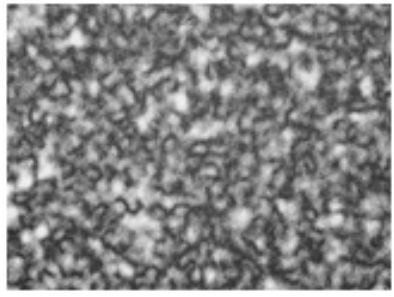

(d) $0,005 \%, 15$ menit

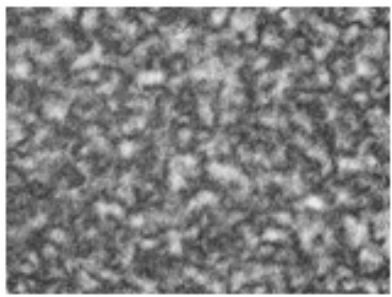

(f) $0,01 \%, 15$ menit

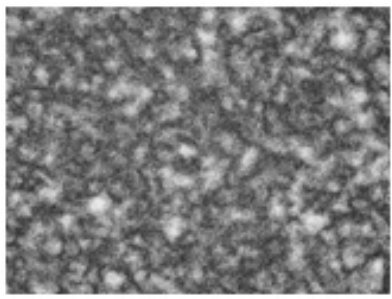

(h) $0,05 \%, 15$ menit

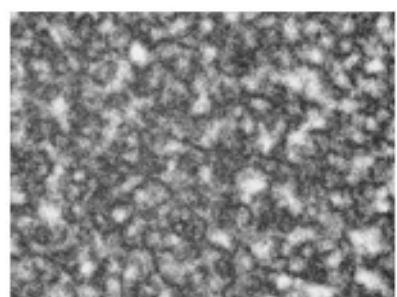

(c) $0,001 \%, 30$ menit

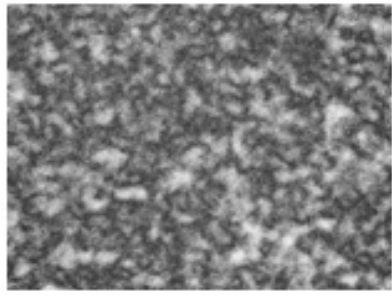

(e) $0,005 \%, 30$ menit

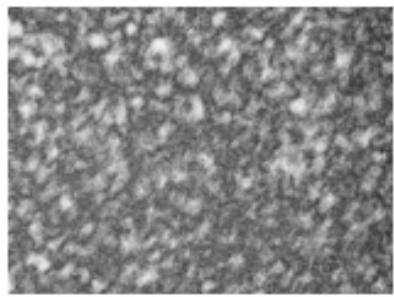

(g) 0,01\%, 30 menit

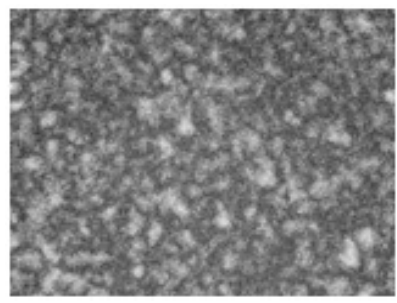

(i) $0,05 \%, 30$ menit
Gambar 2: Perbandingan pola spekel terhadap variasi konsentrasi dan waktu perendaman.

kontras spekel setelah direndam formalin mengalami penurunan dibandingkan dengan nilai kontras sebelum direndam formalin. Pada Gambar 3 dan Gambar 4 diperlihatkan pengaruh konsentrasi terhadap nilai kontras, sedangkan pada Gambar 5 diperlihatkan pengaruh variasi waktu perendaman terhadap perubahan nilai kontras.

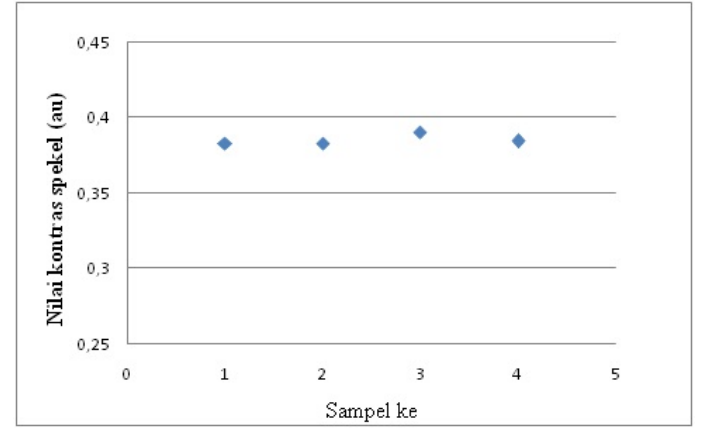

Gambar 3: Nilai kontras spekel tomat sebelum direndam formalin.

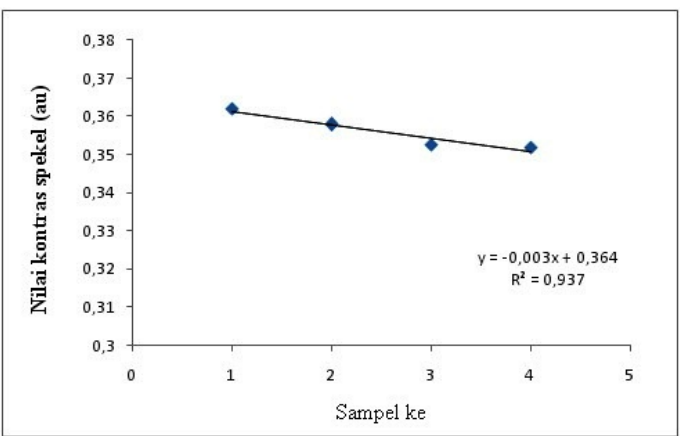

Gambar 4: Nilai kontras buah tomat setelah diformalin dengan variasi konsentrasi.

Penurunan nilai kontras secara keseluruhan dapat dilihat pada Gambar 6. Secara keseluruhan menunjukkan perubahan nilai kontras spekel terhadap variasi konsentrasi dan waktu perendaman. Setiap perubahan konsentrasi memperlihatkan perubahan nilai kontras spekel citra yang dihasilkan. Pada konsentrasi kecil nilai kontras tidak terlalu berpengaruh tetapi semakin tinggi konsentrasi formalin nilai kontras semakin turun, sedangkan dengan penambahan waktu perendaman nilai kontras cenderung semakin turun untuk setiap variasi konsentrasi. Hal ini juga ditunjukkan dengan arah regresi yang semuanya negatif. Nilai regresi mengindikasikan semakin lama perendaman, nilai kontras semakin turun.

Metode LSI menunjukkan responsivitas dan sensitivitas yang baik dengan terdeteksi perubahan kontras yang kecil dari sampel tomat. Tomat dengan konsentrasi kecil 0,001\% dan $0,005 \%$ memberikan pengaruh yang kecil pada nilai kontras. Dengan konsentrasi yang sangat kecil, perubahan nilai kontras pun sangat kecil, dengan responsivitas dan sensitivitas yang baik perubahan tersebut dapat dideteksi.

Nilai kontras dapat digunakan untuk membedakan tomat yang mengandung formalin dan tanpa formalin, sesuai dengan hasil pengamatan dimana nilai kontras mengalami perubahan akibat adanya perlakuan dengan formalin. Secara umum pengamatan kontras spekel jika dikaitkan dengan formalin pada tomat, menunjukkan bahwa formalin terdeteksi dengan perubahan kontras spekel pada tomat tersebut. Tomat yang mengandung formalin memiliki nilai kontras yang ke- 


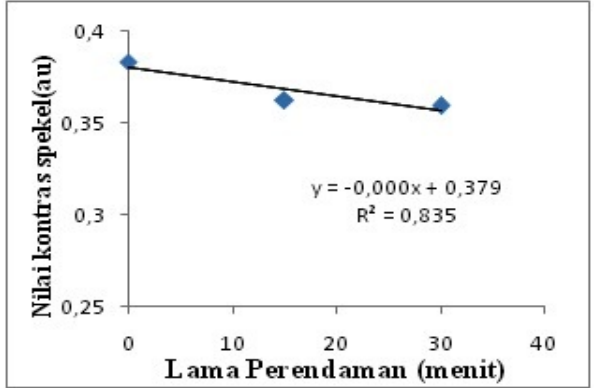

(a) konsentrasi formalin $0,001 \%$

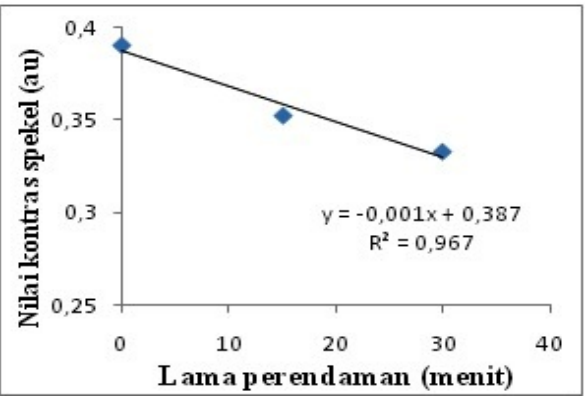

(c) konsentrasi formalin $0,01 \%$

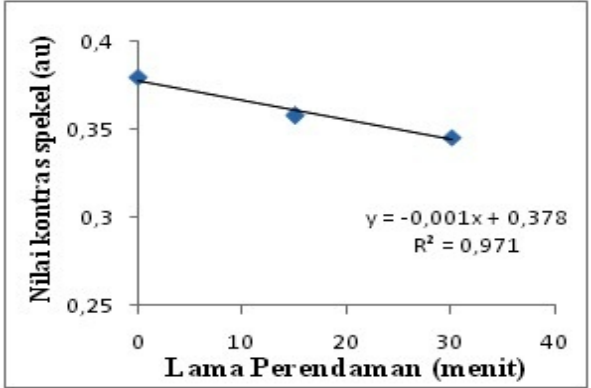

(b) konsentrasi formalin $0,005 \%$

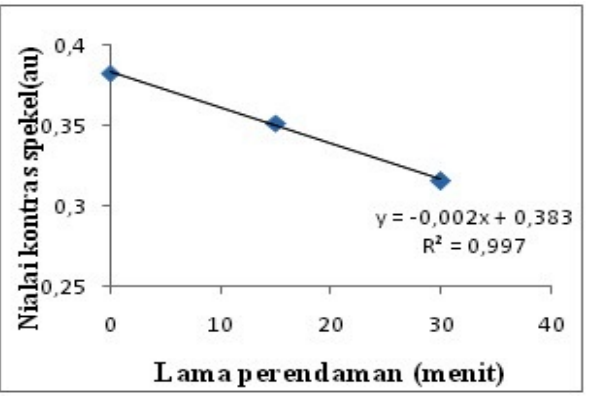

(d) konsentrasi formalin $0,05 \%$

Gambar 5: Perubahan nilai kontras terhadap variasi waktu perendaman dalam formalin.

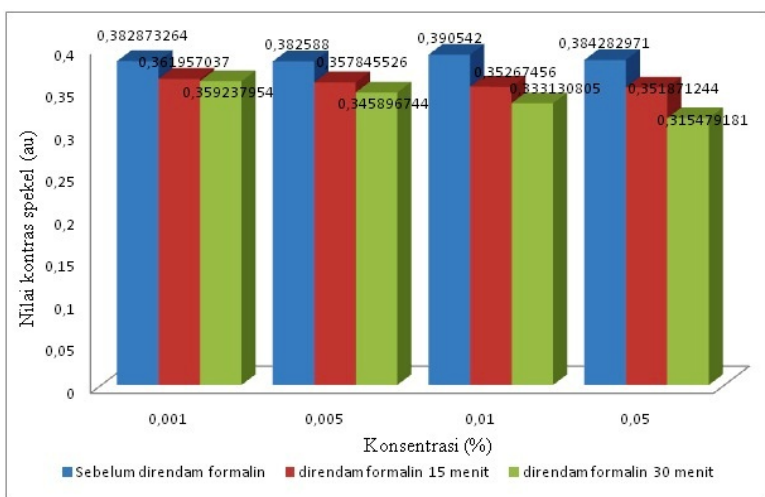

Gambar 6: Perubahan nilai kontras terhadap variasi konsentrasi dan waktu perendaman.

cil dibandingkan dengan tomat tanpa formalin, karena adanya lapisan baru yang terbentuk setelah direndam formalin. Semakin tebal lapisan nilai kontras akan semakin kecil.

Lapisan pada permukaan yang terbentuk setelah direndam formalin diperlihatkan pada dilihat pada Gambar 7. Jika penambahan konsentrasi dan lama perendaman dihubungkan dengan nilai kontras spekel maka dapat disimpulkan bahwa dengan bertambahnya konsentrasi dan lama perendaman berbanding terbalik dengan nilai kontras spekel yang dihasilkan.

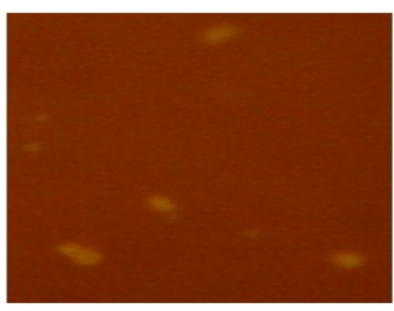

(a) Tanpa Formalin

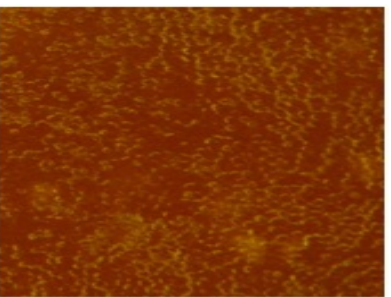

(b) Formalin 0,001\%

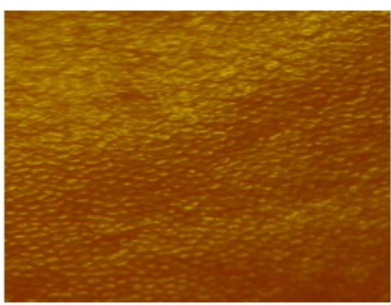

(d) Formalin $0,01 \%$

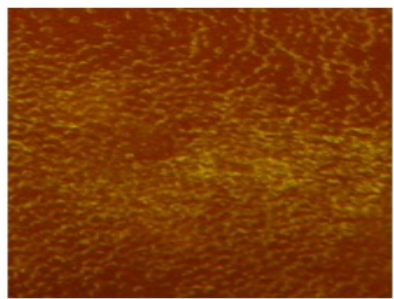

(c) Formalin 0,005\%

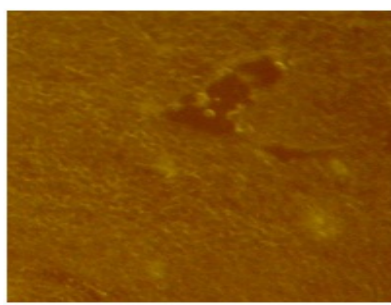

(e) Formalin 0,05\%
Gambar 7: Permukaan tomat dilihat dengan mikroskop optik. 


\section{SIMPULAN}

Berdasarkan hasil penelitian ini, maka didapat beberapa simpulan yaitu:

1. Citra spekel tomat dapat dihasilkan menggunakan sistem LSI.

2. Nilai kontras pola spekel tomat dapat digunakan untuk membedakan tomat tanpa formalin dengan tomat berformalin.
3. Nilai kontras buah berformalin lebih kecil dibanding dengan nilai kontras tanpa formalin.

4. Metode LSI memilki responsivitas dan sensitivitas yang baik dengan terdeteksi perubahan kontras yang kecil.

5. Konsentrasi larutan formalin dan lama perendaman berbanding terbalik dengan nilai kontras spekel yang dihasilkan, semakin tinggi konsentrasi dan waktu perendaman, nilai kontras akan semakin kecil.
[1] H.J. Rabal, and R.A. Braga, Dynamic Laser Speckel and Applications (Optical science and engineering: 139, Taylor \& Francis Group, LLC, 2009).

[2] Z.M. Ansari, and A.K. Nirala, Activity Assessment of Fruits Using the Methods of Inertia Moment and Absolute Value of the Differences (Biomedical Optics Laboratory, Department of Applied Physics, Indian School of Mines Dhanbad, India, 2012).

[3] Tamaki, et al., Invest.Opt.Mol.Vis.Sci., 35, 3825-34 (1994).

[4] R. Apsari, R., Sistem Fuzzy Berbasis Laser Speckle Imaging untuk Deteksi Kualitas Enamel Gigi Akibat Paparan Laser ND:YAG, Disertasi, PPs Universitas Airlangga, Surabaya, 2009.

[5] Harmadi, Aplikasi Pola Spekel Akusto-Optik untuk Pendeteksian Vibrasi Akustik pada Dental Plaque Biofilm, Disertasi, PPs Uni- versitas Airlangga, Surabaya, 2011.

[6] I.S. Rahmawati, dkk., Pengaruh Perlakuan Konsentrasi Kalsium Klorida $(\mathrm{CaCl}-2)$ dan Lama Penyimpanan terhadap Kadar Asam Askorbat Buah Tomat (Lycopersicum esculentum Mill.), Laboratorium Biologi Struktur dan Fungsi Tumbuhan Jurusan Biologi F, MIPA UNDIP, 2011.

[7] T. Dewanti, dkk., Aneka Produk Olahan Tomat Dan Cabe, Jurusan Teknologi Hasil Pertanian, Fakultas Teknologi Pertanian, Universitas Brawijaya , Malang, 2010.

[8] J.W. Goodman, Speckle Phenomena in Optic; Theory and Application (Robert and Co., Englewood, Colorado, 2007).

[9] J.W. Goodmann, J.Opt.Soc.Am, 66, 1145 (1976). 